Zagadnienia Rodzajów Literackich, LX, z. 3

PL ISSN 0084-4446

DOI: $10.26485 / Z R L / 2017 / 60.3 / 3$

Katarzyna Stadnik

Uniwersytet Marii Curie-Skłodowskiej w Lublinie*

\title{
Popularisation of Science as Translation: A Cultural Linguistic Account
}

\begin{abstract}
In the paper, we focus on the question of science popularisation as translation. We develop a Cultural Linguistic account of how conceptual metaphors help tailor the abstract conceptual content to the needs of non-experts. Since the issue linking the various topics in our paper is the mind-reality relation, we offer a linguistic analysis of selected conceptual metaphors in Michał Heller's Philosophy of Chance. We provide insights into the worldview emerging from the author's narrative about the evolution of the concept of CHANCE.
\end{abstract}


* Zakład Językoznawstwa Kulturowego Instytutu Anglistyki Uniwersytetu Marii Curie-Skłodowskiej w Lublinie

al. Marii Curie-Skłodowskiej 4a, 20-031 Lublin

e-mail: katarzyna.stadnik@poczta.umcs.lublin.pl 


\section{Introduction}

Scientific discovery builds on imaginativeness, one of the hallmarks of human cognition. What is also unique about humans is cooperative communication, a capacity fundamental to the establishment of culture. In general, people tend to share knowledge. While we can utilise different forms of communication, language remains a special cognitive tool that facilitates sharing what we already know, and that helps create new knowledge, which may go beyond information available to humans in physical reality. Thanks to language we can access knowledge that otherwise might be inaccessible, for instance, by virtue of being out of our reach, as it is the case with learning about phenomena in the quantum world, and/or because of being too hard for us to grasp, as it is the case with scientific theories forged by experts. Scientific discourse implies a special use of language. While scientific communication tends to be hermetic, publications popularising science aim to facilitate a better understanding of abstract ideas among general readership.

It should not come as a surprise to state that tailoring scientific discourse to the needs of a general audience entails interlingual translation (Jakobson 1959). As the etymology of translation shows the origins of the lexical item are traceable to the sense of 'being over, carry over' or 'transfer' (Barnhart 1998: 1160). The extensions of the meanings in the respective OED dictionary entry, including 'conversion of something from one form or medium into another' ${ }^{1}$, are metaphorical in nature. In Polish, even though the lexical items przektad, ttumaczenie are synonymous with translacja 'translation', subtle differences in the respective meanings occur. That is, pretetad conveys the idea of interlingual and intralingual translation, whereas ttumaczenie adds an interpersonal aspect of excusing oneself, and the persuasive component of explaining, justifying, accounting for something. Popularisation of science also involves a rhetorical element in that it entails the need to reduce conceptually complex ideas into shareable objects of thought. One effective tool helping to achieve this aim is metaphor. In scientific discourse, metaphors may perform different functions, including the creation of new ideas (see Tabakowska 2015). The formation of a metaphor aptly capturing relevant conceptual correspondences may pose a great challenge, since its use implicates a number of interrelated factors of cognitive, linguistic, and cultural nature.

1 Retrieved from https://en.oxforddictionaries.com/definition/translation [access: 14 February 2017]. 
In the paper, we use the metaphor SCIENCE POPULARISATION AS TRANSLATION to help us structure our discussion of how humans share knowledge. As a heuristic device, the metaphor enables us to focus on the cognitive-cultural aspects of knowledge transmission.

\section{Scientific thought and the mind-reality problem in a cognitive-cultural perspective}

The paper focuses on the transmission of scientific ideas mediated through narrative discourse. As such, it concerns the relation between the mind and reality. We take an experientialist perspective on the question of universality/relativity of human knowledge, indicating that it seems inopportune to suggest that the two approaches are necessarily mutually exclusive. As Kövesces (2006) explains, relativity does not preclude universality in knowledge. The author argues that people coming from different cultures share a certain set of universal cognitive processes used to construct meaning. In simple terms, our physical embodiment provides a universal foundation for communication between cultures.

However, it can be suggested that the human mind is situated. As Barsalou (2016; original italics) has it, "[ $\mathrm{t}]$ he crux of the grounded approach is understanding how the modalities, the physical environment, the social environment, and the body contribute to cognition, playing central roles in the diverse forms it takes". Viewing mental activity as situated implies that cognition and culture are mutually constitutive. While the bond entails that our minds are shaped culturally, it is equally important that individuals mentally construct the world and negotiate their conceptualisations in interaction occurring in particular socio-cultural milieu, which contributes to the emergence of an intersubjectively shared conceptual order.

Situatedness does not prevent community members from acquiring new knowledge from sources other than those available within the bounds of their own community. Virtually no culture exists in separation from other groups. Globalisation is one prominent indicator of the negotiability of knowledge that can be shared indirectly via different information carriers and media, including written texts. In intercultural communication, disseminating ideas may entail ideological clashes between competing worldviews. Science promotion can be viewed as a mediating practice generating the "fusion of horizons" between various perspectives on the mind-reality relation.

\section{Cultural Linguistics and the dissemination of knowledge}

We find the Cultural Linguistic framework particularly well-suited to the task of enquiring about the nature of the bond underlying human conceptualisation of the world and reality, as it explores the relation between language, culture, and conceptualisation.

The grounded view of cognition draws on the context principle that prioritises the contextualisation of mental activity in the environment, both physical and social-cultural. Barsalou, Wilson, and Hasenkamp (2010) speculate about the decontextualisation of phenomena under scientific investigation, discussing the use of nominalisation in academic discourse. Using nominals entails imparting information about objects as spatially bounded and stable in time, which is conducive to treating them as relatively context-free entities (e.g., emotion, perception vis-à-vis emote, perceive). Therefore, the use of the noun cognition might give rise to the less dynamic construction of mental activity as bounded in the space "between the ears". 
The study of the relation between language, culture, and cognition is a broad area of research (see also A Companion to Cognitive Anthropology 2011). Therefore, we narrow the scope of our investigation to one particular approach: Cultural Linguistics. Due to the goals of our study, we strongly emphasise the Cognitive Linguistic origins of the Cultural Linguistic research strain. Based on this, we employ the Cognitive Linguistic methodological principle of converging evidence. In the words of Evans and Green (2006: 17), "a model must not only explain linguistic knowledge, but must also be consistent with what cognitive scientists know about other areas of cognition".

With respect to our discussion on the need to contextualise phenomena under study, we suggest that the terms cultural cognition and cultural conceptualisation might lead to some oversimplification of the intricate nature of human interaction. In Cultural Linguistics, it is claimed that "[c]ultural cognition embraces the cultural knowledge that emerges from the interactions between members of a cultural group across time and space" (Sharifian 2015: 476). However, it seems that cognition does not need to be tagged 'cultural' to be so. Cognition is cultural in that it emerges from the locally situated mental activity of individuals embedded in the history of lived experience of a given community. However, what leads to scientific discovery and progress is joint endeavour, the success of which often depends on collective action undertaken across community boundaries.

\section{Science popularisation: Conceptual challenges}

Our study is designed to trace the ways in which the community's knowledge of the world is reconceptualised as the relevant information is restructured to meet the demands of the popularisation of scientific thought. One aspect of the problem is the asymmetry in knowledge between experts and non-professional readers. Barsalou's (1991) idea of goalderived categorisation may shed light onto the issue of folk and expert categorisation insofar as professionals and non-experts might have different goals. Variation in categorisation between folk and expert theories might derive from divergent goals due to differences in the situatedness of particular individuals. Seen in this light, situatedness implies particular kinds of barriers to sharing knowledge, making some domains of knowledge more or less accessible to a particular individual.

Professional written communication can be characterised by two conflicting demands: the constraint of conventionality, particularly visible in lexical and grammatical choices shaping the linguistic form of a scholarly text, and the need for innovation, for instance, to ensure rhetoric effectiveness, but also to express novel ideas. Since academic texts usually occur in institutionalised contexts, and their main audience is professional community. Academic publications may put an extra strain on a non-expert reader in that they require an expert understanding of terminology. Particular lexical items used as specialist terms may prompt for different conceptualisations, depending on the demands of the context in which they appear. Barsalou (2009: 245) explains that as people gather experience, the knowledge of recurring situations becomes entrenched in memory. Such entrenched knowledge can be activated to support cognitive processes by pattern completion inference, which helps the agent form useful predictions. On our cognitively-based account, meaning construction depends on specific linguistic choices: words do not "carry" meaning, but prompt for conceptualisation. The meaning of words, including specialist terms, 
is not usually processed in isolation, but relative to a specific background. Thus, some specialist terms can hinder or facilitate sense-making, depending on the reader's cognitive resources.

\section{A situated approach to concepts and conceptualisation}

One challenge of constructing the meaning of some specialist terms is that due to the evolution of the underlying conceptual content that involves the migration of relevant concepts between various experiential contexts they have come to be used in diverse domains of human activity. Thus, since "situations provide essential information for representing and understanding concepts" (Barsalou 2009: 253), helping a non-expert understand a specialist term might require contextualising the word in a situation recognisable for the non-professional reader so that they can form correct inferences. Problems with comprehension may arise when the same word applies to a host of potentially relevant situations. This may explain why some concepts in science are deemed "inexact", while specialist terminology bears the infamous label of being "vague".

For illustration we briefly discuss the concept of PROBABILITY, which does not lend itself to a hard-and-fast interpretation. As we read in Stanford Encyclopedia of Philosophy:

Probability is virtually ubiquitous. It plays a role in almost all the sciences. It underpins much of the social sciences - witness the prevalent use of statistical testing, confidence intervals, regression methods, and so on. It finds its way, moreover, into much of philosophy. (...) Since probability theory is central to decision theory and game theory, it has ramifications for ethics and political philosophy. It figures prominently in such staples of metaphysics as causation and laws of nature. It appears again in the philosophy of science in the analysis of confirmation of theories, scientific explanation, and in the philosophy of specific scientific theories, such as quantum mechanics, statistical mechanics, and genetics. It can even take center stage in the philosophy of logic, the philosophy of language, and the philosophy of religion. Thus, problems in the foundations of probability bear at least indirectly, and sometimes directly, upon central scientific, social scientific, and philosophical concerns. The interpretation of probability is one of the most important such foundational problems ${ }^{2}$.

It follows that concepts are not tied to specific domains (here: of disciplinary nature), which is one of the reasons why grounded cognition should not be rendered in terms of culture-specificity. In arguing so, we point out the fuzzy boundaries of local cultures, their propensity for conceptual evolution, and the human capacity for blending conceptualisations from different communities.

It is instructive to consider one specific conceptualisation from the domain of scientific discourse. After Bohr introduced the metaphor of ATOM AS A SOLAR SYSTEM, it has been used in pedagogy (Sweetser and Dancygier 2014: 204). As a result, it has been integrated into the encyclopaedic knowledge of members from different communities. Can we conclude that the metaphor is an instance of cultural conceptualisation? If yes, what culture should we allocate it to? Attempts at assigning the model to any particular culture (and also, by this logic, language) reveal some problems with defining cultural cognition as "heterogeneously distributed across the members in a cultural group" (Sharifian 2008: 113), and language as "one of the primary mechanisms for storing and communicating

2 Retrieved from https://plato.stanford.edu/entries/probability-interpret/ [access: 14 February 2017]. 
cultural conceptualizations" (Sharifian 2009: 168). At what level of conceptual granularity should be construed the terms culture and language in order to render the definitions viable? Our answer presupposes the sociocultural situatedness of a community member whose knowledge, beliefs and values are not fixed, but liable to change in the course of interaction with the world, including interaction with other humans, also members of other communities, as well as interaction with the physical environment encompassing various information carriers. Situatedness does not predispose humans to remain constrained by the limits of their language and/or locally available knowledge, values, and beliefs.

Furthermore, describing the ways in which probability is conceptualised as "cultural" would not be merely misleading, as implied above. It might also produce an oversimplification of the complex conceptual nexus in which PROBABILITY should be placed. As the overview clearly indicates, PROBABILITY is a notion which for its interpretation depends on other interrelated concepts. Other connected notions include CAUSALITY, EXPECTATION, EXPLANATION, to name but the few featured in the excerpt. Moreover, each of these notions can be differently constructed, depending on the goals of the researcher who considers them relative to a specific domain.

\section{Science popularisation: Overcoming barriers to scientific communication}

How do humans overcome problems with scientific communication? It is useful to shed light on how knowledge can be conceptualised in a manner that ensures co-operation. Two metaphors relevant to our discussion can be identified. Whereas the first underscores efforts to impose conceptual order onto the flux of reality, the other indicates how humans deal with this difficulty in practice.

The conceptual metaphor KNOWLEDGE IS A TREE, rooted in the Biblical tradition, appears to implicitly motivate the pursuit for consilience, the endeavour to unify knowledge from different branches of scientific and humanistic study. Whether obtaining a universal view of the world, based on a widespread understanding of reality, is attainable remains an open question. Perhaps complexity science may offer a viable solution to the problem which many people deem a quixotic quest (see also Mitchell 2009). The conception of consilience encapsulates human inclination to share goals and co-operate in search of attaining a better understanding of reality despite a plethora of divergent viewpoints from which the world can be mentally constructed. It seems that, to some extent, the popularisation of science may foster interdisciplinary research. For instance, linguists interested in mastering statistics, the knowledge of which is necessary to conduct corpus-based studies, may well use accessible publications on statistics dedicated to nonprofessional readers.

The conceptual metaphor KNOWLEDGE AS A VALUABLE RESOURCE may help account for the general consensus as to the need for science popularisation and the necessity to use knowledge to the benefit of the whole community. From this perspective, the diffusion of science takes the form of collective endeavours to manage knowledge in a most effective way. The metaphor reveals that the concrete domain of useful physical resources can help conceptualise the intangible reservoir of ideas contained in the human mind, additionally providing a conceptual point of convergence for joint enterprises. Knowledge management, however, is not tantamount to the management of information, in particular in the area of science (see also Babik 2008). Information can be defined as contextualised 
data that can be used by humans for different purposes, whereas knowledge entails the mental activity of a cognising individual (Fazlagić 2014; see also Grucza 2015). Information can exist independently of its carrier (Fazlagić 2014: 32). In contrast, knowledge involves human activity, it is viewed as situated in a specific time and space, and thus integral to the culture of a given community (Fazlagić 2014: 33). Derived from human experience, knowledge is constitutive for the group's identity as well (Fazlagić 2014: 33).

While metaphors may facilitate a better understanding of a phenomenon, they can also conceal some aspects of the problem, which reduces the complexity of the issue. The metaphor KNOWLEDGE AS VALUABLE RESOURCE may spur the conceptualisation of KNOWLEDGE as A SHAREABLE OBJECT, as attested in the phrase knowledge transmission. This does not seem entirely correct since knowledge is created by the individual on the basis of the information received. It might be more accurate to refer to the management of information carriers and multimodal communication channels instrumental in managing knowledge.

Communities that carefully manage their knowledge make continuous efforts to foster its creation, detection, discovery, organisation, evaluation, acquisition, protection, as well as encourage its members to share their knowledge, and re-use the knowledge they have to lower the costs of its creation (Fazlagić 2014: 23). This perspective lends a new overtone to the metaphor SCIENCE POPULARISATION AS TRANSLATION. Specifically, the translator-populariser is seen as an agent acting on a market where commercial forces combine to verify the value of his/her offer. Despite the somewhat daunting conclusion that non-experts might put a price tag on professional knowledge, we argue that in the domain of science popularisation effective knowledge management can boost efforts to disseminate scientific thought across community members. It is important to enlist experts' co-operation, because an experienced populariser of science is responsible for ensuring successful transfer of scientific ideas. Since in cognitive-cultural terms culture can be conceptualised as a toolkit (CULTURE AS TOOLKIT), comprising linguistic and non-linguistic resources that help impart information, science popularisation in this respect may take the form of intersemiotic translation, including forms such as information visualisation of various kinds, multimedia presentations, conferences, or scientific fairs. As such, the problem falls beyond the scope of the paper.

\section{Science popularisation as translation: The (in)visibility of the translator}

The information contained in the scientific narrative undergoes changes, many of which might be substantial insofar as they greatly reduce the complexity of a scientific problem. Apart from popularising scientific thought by making it more accessible to the reader without professional background and satisfying the reader's thirst for knowledge, such publications promote a particular worldview, or a specific perspective from which reality is construed. We deem this component ideological. Following Koller (2015: 239-240), ideology can be seen as

a (metaphorical) network of beliefs that gives rise to expectations, norms and values about events, ideas and people. When we take part in events, encounter people and their ideas expressed, we compare those experiences against our ideologically informed expectations, norms and values, and thereby evaluate and categorize experiences. 
A cognitively-based study can reveal ideological aspects of discourse. For instance,

the fact that discourse producers highlight and hide particular semantic features through metaphor $(. .$.$) makes it possible to trace ideologically vested choices in the generation and usage of$ complex metaphors. (...) As such, metaphoric expressions may help to reify cognitive models governing discourse, and underlying metaphors may partly determine the surface structure of text, while texts will reify and conventionalize particular conceptual metaphors. (Koller 2012: 241)

The narrative form implicates a range of possible ways of organising the knowledge to be shared, including the issue of what information to include in the story, and how to interconnect its various threads. This may beg the question of how causality is construed in a narrative. As Dancygier (2012: 61) explains, in narratives viewpoint can be ideological, "when the very selection of facts presents the story in a specific light".

Furthermore, the consideration of the ideological stance from which a particular set of scientific ideas is construed seems vital in that scientific discourse unavoidably shades into the realm of the relations of power within a community. Both scientists themselves and individuals actively publicising science to a wider audience of non-experts are often assumed to possess authority deriving from their expert knowledge. Once again the metaphor SCIENCE PROMOTION AS TRANSLATION demonstrates its explanatory potential. On the one hand, the science propagator can be viewed as intercultural mediator, much like many translators are due to their familiarity with different cultures, as well as familiarity with what might not be known to members of a given community due to linguistic barriers. On the other, the science propagator cannot be regarded as "invisible", or ideologically-neutral, which corresponds to the trend to undermine the "invisibility" of the translator in Translation Studies.

Whether renowned scientists or not, all humans fall victim to their own limited insight, often constrained by their beliefs and values guiding how they make sense of reality. The problem of human cognitive constraints, or the idiosyncrasy of the human mind, encompasses power relations in science. Successful scientific dialogue, whether intra- or international, requires the propensity for co-operation. This can be best illustrated by the case story about the discovery of electron spins. Ralph Kronig's milestone discovery and his subsequent decision against pursuing his intuition on receiving a strong critique from Wolfgang Pauli is particularly instructive:

Ehrenfest's encouraging response to his students ideas contrasted sharply with that of Wolfgang Pauli. As it turned out, Ralph Kronig (...) had come up with the idea of electron spin several months before Uhlenbeck and Goudsmit. He had put it before Pauli for his reactions, who had ridiculed it, saying that "it is indeed very clever but of course has nothing to do with reality". Kronig did not publish his ideas on spin. No wonder that Uhlenbeck would later refer to the "luck and privilege to be students of Paul Ehrenfest"

We highlight potential ethical challenges involved in science communication, which entails human integrity implicated in achieving goals. The question implies normative expectations relative to co-operation (when having convergent goals) and competition (participants with opposing goals). Not every professional may be ready to acknowledge their

3 Retrieved from https://www.lorentz.leidenuniv.nl/history/spin/spin.html [access: 14 February 2017]. 
own limited insight, and even fewer might be willing to reveal their vested interests. This stands in sharp contrast with the situation on a commercial market where the laws of supply and demand can assess the value of an unsuccessful translation.

While Kroning fell victim to the cognitive bias connected with the authority of the renowned colleague, the readers of popular books on science may also be less inclined to critically evaluate the ideological stance from which scientific ideas are disseminated. Likewise, another parallel between the populariser and the translator can be found in that errors made by translators can go unnoticed since the reader may lack in expertise and/ or access to the original work necessary for the proper evaluation of a given translation.

\section{The concept of CHANCE in Michał Heller's Philosophy of Chance}

Michał Heller's Philosophy of Chance is a publication promoting scientific thought. As a cosmologist and a philosopher, Heller has been a successful knowledge disseminator, and promoter of interdisciplinary dialogue, combining insights from domains as varied as mathematics, theology, and the history of science. His Philosophy of Chance blends humanistic and scientific perspectives on the nature of the mind-reality problem, as the author uses metaphors so as to shed light onto physical phenomena often inaccessible to the human naked eye, and thus hardly imaginable for the non-expert reader.

The narrative outlines the philosophical origins of the abstract concept of CHANCE against the background of theoretical considerations concerning the evolution of PROBABILITY. It is the philosophical framework that provides a theoretical foundation enabling Heller to move freely across disciplinary borders. As the author repeatedly stresses, his narrative is not a history of either probability calculus or chance per se. In Heller's own words,

If I were to dedicate this book to someone, it would be to Richard Dawkins and William Dembski. They are worlds apart, yet they have even more in common. They stand divided by their views on the theory of evolution. Dawkins considers it to be a "blind watchmaker" who explains everything, while in Dembski's view it is full of "irreducibly complex situations" that testify to Intelligent Design. (...) In the book (...) I put forward my own position, equally distant from the views of one and the other. (...) My broader context is constituted by the "philosophy of chance" (...). (Heller 2013: 9)

Regardless of the specific stance on the origins of the universe, the proponents of each approach use linguistic expressions motivated by conceptual metaphors to give increased salience to the ideological component of meaning they intend to convey. Elsewhere in the book, Heller says,

[the] extraordinary symphony of cosmos can be approached from different points of view. (...) Chance occurrences explain nothing, because they themselves demand an explanation. They are so subtly intertwined with the cosmic structure that without it they lose their import and cannot exist. (....) everything is part of the one Great Matrix. I would call it Intelligent Design, but this beautiful name has been compromised, therefore I prefer to use a phrase so often used by Einstein: "the Mind of God". And the purpose of science is nothing else but to decipher this "Mind of God". (Heller 2013: 13) 
The BLIND WATCHMAKER metaphor invokes the idea of CAUSALITY enmeshed in a mechanical view of the universe (THE UNIVERSE IS A CLOCK) ${ }^{4}$, whereas the notion of INTELLIGENT DESIGN encourages us to construe CAUSALITY in terms of God's Grand Design (CREATION IS A PROJECT). However, Heller's reference to the MIND OF GOD metaphor implicates a perspective distinct from the two other approaches, which give emphasis to CAUSALITY, but models it in contrasting ways. Heller's UNIVERSE IS A MATRIX metaphor enhances the reader's attentiveness to the world's inherent complexity ${ }^{5}$. The worldview that can be gleaned from Heller's metaphors is not free from ideological engagement, but this involvement is contextualised in a relevant historical and theoretical background. As a result, the whole narrative serves explanatory purposes. Causality is presented as a derivative of the Cosmic Matrix. This is achieved by construing CAUSALITY via the selection of particular events contributing to our contemporary understanding of CHANCE and PROBABILITY. The selection is not accidental, but dictated by Heller's overall narrative goal of presenting the philosophy of chance.

The phrase symphony of cosmos reveals the underlying metaphor COSMOS IS MUSIC, which, in turn, may evoke in the reader's mind the expression music of the spheres (see also Lewis 1964). Heller himself uses a musical metaphor to structure his narrative as "a cosmic fugue with a prelude and a coda", with the corresponding parts of the book entitled "The Prelude", "The Fugue", and "The Coda", respectively. As the OED definition suggests, a fugue is "a contrapuntal composition in which a short melody or phrase (the subject) is introduced by one part and successively taken up by others and developed by interweaving the parts". The form of the fugue is characterised by "mathematical intricacy, formality, symmetry, and variety". This analogy helps the reader construct the metaphor PHILOSOPHY OF CHANCE IS (LISTENING TO) THE FUGUE. Specifically, since events are often carved out of the fabric of our everyday lives on the basis of the perceived changes in reality around us $^{7}$, using the notion of the fugue consisting of counterpoints establishes a useful analogy helping the reader perceive the described events as interrelated turning points in the history of science. The metaphor instructs how to interconnect various conceptions presented in the narrative. As such, it is an ingenious teaching aid, the pedagogical usefulness of which can be appreciated in particular in connection with the need to establish a common ground with the reader who has to create their own knowledge on the basis of the prompts given.

$4 \quad$ The universe started to be viewed as a machine after the collapse of the Aristotelian worldview, during the transition to the Newtonian outlook on reality. This change triggered a chain of interrelated conceptual adjustments, including the idea of God, who started to be conceived as "a sort of watch-maker, that is, one who designed and constructed the universe, and set the universe in motion. But thereafter the universe runs along without the constant intervention needed in the previous worldview" (DeWitt 2010: 179).

5 According to DeWitt (2010: 348), "the universe [the metaphors in science] suggest is not like anything we have experienced. That is, the nonlocal influences demonstrated by the Aspect experiments suggest a universe that is not like anything with which we are familiar. A universe that allows for instantaneous influences between events that have no connection whatsoever between them is not a universe that is like anything familiar to us. (...) For the first time in (at least recorded) history, we may be metaphorless". Heller's creativity demonstrates that we are apparently not.

6 Retrieved from https://www.britannica.com/art/fugue [access: 14 February 2017].

7 We suggest that establishing event boundaries might affect how causality in is construed in that "[e]vent boundaries correspond to the completion of one goal or intentional act and the initiation of a new goal or intentional act" (Tversky and Zacks 2013). Event boundaries entail some change, and can thus be seen as particularly informative. 
How is CHANCE conceptualised in Heller's book? In the Prelude section, Heller describes human endeavour of understanding the role of chance events in the structure of the universe as "taming of chance" as a result of the development and application of mathematical tools. It stands to reason to model the initial understanding of CHANCE as LACK OF (PHYSICAL) CONTROL, prompting a conceptualisation based on force dynamics. The erstwhile conceptualisation of CHANCE derived from construing it as a collapse of rationality. With the emergence of probability theory, chance came to be constructed as integral to the mathematical structure of the world, and thus, as a measurable phenomenon connected with the probabilistic properties of the world. This generalisation of CHANCE in terms of MEASUREMENT had been hardly conceivable prior to the efforts made by the precursors who strived to curb chance relative to statistical data that at first came from domains such as gambling. Among the precursor Heller counts Pascal and Fermat. Commenting on the exchange of letters between them, the author says

Antoine Gombauld (...) was a man of experience and a passionate gambler. (...) When he met Pascal during a social event, he posed a certain problem to him: A game of dice must be interrupted before the players can finish. How to divide the stake between the two players who cannot complete the game? After a moment's thought, Pascal answered that every player should receive an amount proportional to the probability that he would win the game if it were finished. (...) Pascal decided to consult Fermat on his considerations. (Heller 2013: 34)

The exchange of letters was the cornerstone of today's probability calculus inasmuch as it allowed the interpretation of a problem to be solved. This enabled the evolution of mathematical methods used to tackle chance and expectation that later developed into the conception of probability.

Overall, Heller's narrative can be viewed as a tool of knowledge transmission and reorganisation of the reader's knowledge. Since words do not "carry" meaning, but prompt for conceptualisations, the narrative should not be regarded as a carrier of knowledge per se. Rather, it constitutes what might be regarded as a complex information-bearing carrier, the structure of which should facilitate knowledge creation. As humans create their knowledge themselves, the populariser's role is to provide some assistance conducive to the formation of inferences on the part of the reader, which have been intended by the author of the publication. In short, the populariser structures the information contained in the text in such a way as to put the reader on the right track to the creation of knowledge. This requires the populariser's expertise to manage the creation of the reader's knowledge by ensuring most effective ways in guiding the reader's comprehension. Nevertheless, the reader's mental effort is equally indispensable.

\section{Conclusions}

How is our account of selected conceptual metaphors in Philosophy of Chance relevant to the issue of SCIENCE POPULARISATION AS TRANSLATION? We conclude our paper by situating the present study in a relevant theoretical background of linguistic conceptions addressing the problem of language, culture, and the mind. Publications disseminating scientific thought and directed at the general reader may foster the creation of knowledge 
in a community. If so, such publications can be useful in the linguistic study of worldviews held within a given community. Exploring such linguistic usage should help uncover ways in which reality is constructed by members of a specific group.

One linguistic conception that may help situate our study relative to the theoretical background of culture, cognition, and language is Jerzy Bartmiński's idea of the linguistic worldview. The scholar develops "the linguistic worldview conception, the 'naive' picture at the very basis of language” (Bartmiński 2009: 23). Importantly,

[t]he worldview is 'naive' in the sense of Apresyan, i.e. constructed by a human being, relative to human measure, anthropocentric, but also adapted to social needs and ethnocentric mentality (Aprean, 1994). This is the conception of linguistic worldview one finds in the basic, most common variant of national language, namely the colloquial variant (or style), whereas in the scientific style the worldview is subjected to strong differentiation with regard to a given discipline and its state of the art.

With regard to the idea of CHANCE, we find a related excerpt in Bartminski,

Different linguistic 'worldviews' can exist within a community of people speaking the same language. (...) Bartmiński, following Wierzbicka, traces los to the Enlightenment period, which promoted a belief in the possibilities of the individual to determine their 'fate'. Dola, on the other hand, is traced to the perspective of the 'simple' peasant, who experiences the determining nature of 'fate' for the individual's life. (Bartmiński 2009: 4)

How can we situate our study relative to the conception of the linguistic worldview? It would seem reasonable to suggest that los is a derivative of a more scientifically informed conceptualisation of the human condition, whereas dola uncovers an utterly naïve perspective onto our place in the universe. Due to the correlation with games of chance, Polish los could then be regarded as a descendant of a collateral line of the conceptual evolution implicated in the emergence of probability calculus, as attested in zdarzenie losowe 'chance event'. In fact, as argued by Wierzbicka, HUMAN LIFE can be seen as LOTTERY (Wierzbicka 1991). By this logic, the worldview underlying Heller's publication should be situated half-way on the naïve to scientific scale, blending components of both kinds of worldviews. Such a balanced interpretation might be gleaned from conceptualisation of LIFE AS A GAME OF CHANCE (Heller 2013: 224), and both BIOLOGICAL EVOLUTION and LIVING ORGANISMS AS DYNAMICAL SYSTEMS (Heller 2013: 207).

What we find problematic is that Bartmiński's linguistic worldview conception implies an arbitrary differentiation of human knowledge into that which is to be considered as naive, and that which is to be construed as scientific. The opposition seems somewhat contrived in that the understanding of what constitutes a scientific idea changes over time. Metaphorically speaking, humans outgrow their worldviews when the older outlooks on reality become obsolete, for instance, due to scientific discoveries. Also, the dichotomy of naïve and scientific worldview calls for reconsideration, because many concepts are not fixed in specific domains, but often migrate between various areas of human activity. For instance, the concept of CHANCE might produce different situated conceptualisations, connected with different goals an individual might have relative to various contexts. 
In conclusion, publications popularising scientific thought may facilitate informationsharing and the subsequent creation of knowledge by the reader. In light of our discussion, one should be wary of confusing the management of knowledge with the management of information. The existence of human co-operation and competition means that individuals differ not only in their contributions to the community's repository of knowledge, but also in the goals they entertain. In view of this, the worldviews emerging from how humans construct reality on the basis of knowledge they have and goals they pursue in specific contexts are negotiable. Adopting a grounded perspective on this problem can help develop a more nuanced approach, based on a situated conception of linguistic meaning, rather than founded on the opposition of the native and the scientific.

\section{Bibliography}

A Companion to Cognitive Anthropology (2011), eds D.B. Kronenfeld, G. Bennardo, V.C. de Munck, M.D. Fischer, Wiley Blackwell, Chichister.

Babik Wiesław (2008), Informacja naukowa jako przedmiot zarzadzania [in:] Zarzadzanie informacja w nauce, ed. D. Pietruch-Reizes, Wydawnictwo Uniwersytetu Śląskiego, Katowice.

Barnhart Robert (1998), Chambers Dictionary of Etymology, Chambers, London.

Barsalou Lawrence (1991), Deriving Categories to Achieve Goals [in:] The Psychology of Learning and Motivation: Advances in Research and Theory, ed. G.H. Bower, Academic Press, San Diego.

- (2009), Situating Concepts [in:] Cambridge Handbook of Situated Cognition, eds P. Robbins, M. Aydede, Cambridge UP, New York.

- (2016), On Staying Grounded and Avoiding Quixotic Dead Ends, "Psychonomic Bulletin \& Review”, August 2016, Volume 23, Issue 4, http://link.springer.com/article/10.3758/ s13423-016-1028-3 [access: 14 February 2017].

Barsalou Lawrence, Wilson Christine D., Hasenkamp Wendy (2010), On the Vices of Nominalization and the Virtues of Contextualization [in:] The Mind in Context, eds B. Mesquita, L. Feldman Barrett, E. Smith, Guilford Press, New York.

Bartmiński Jerzy (2009), Aspects of Cognitive Ethnolinguistics, Equinox, London-Oakville.

Dancygier Barbara (2012), The Language of Stories. A Cognitive Approach, Cambridge UP, Cambridge.

DeWitt Richard (2010), Worldviews: An Introduction to the History and Philosophy of Science (2nd edition), Wiley-Blackwell, Chichister.

Encyclopaedia Britannica, https://www.britannica.com [access: 14 February 2017].

Evans Vyvyan, Green Melanie (2006), Cognitive Linguistics. An Introduction, Edinburgh UP, Edinburgh. 
Fazlagić Jan (2014), Innowacyjne zarzadzanie wiedza, Difin, Warszawa.

Grucza Sambor (2015), Jezy/ki jako “instrument” predykacji wiedzy prayszłości [in:] Tekst naukony i jego przekład, eds A. Duszak, A. Jopek-Bosicka, G. Kowalski, Universitas, Kraków.

Heller Michał (2013), Philosophy of Chance. A Cosmic Fugue with a Prelude and a Coda, trans. R. Śmietana, Copernicus Center Press, Kraków.

Jakobson Roman (1959), On Linguistic Aspects of Translation [in:] On Translation, ed. R. Brower, Harvard UP, Cambridge, MA.

Koller Veronica (2015), Cognitive Linguistics and Ideology [in:] The Bloomsbury Companion to Cognitive Linguistics, eds J. Littlemore, J. R. Taylor, Bloomsbury Academic, London-Oxford.

Kövesces Zoltan (2006), Language, Mind, and Culture, Oxford UP, Oxford.

Lewis Clive Staples (1964), The Discarded Image: An Introduction to Medieval and Renaissance Literature, Cambridge UP, Cambridge.

Mitchell Melanie (2009), Complexity. A Guided Tour, Oxford UP, Oxford-New York.

Oxford English Dictionary, https://en.oxforddictionaries.com [access: 14 February 2017].

Sharifian Farzad (2008), Distributed, Emergent Cultural Cognition, Conceptualisation, and Language [in:] Body, Language and Mind: Volume 2: Sociocultural Situetedness, eds R. M. Frank, R. Dirven, T. Ziemke, E. Bernárdez, Mouton de Gruyter, Berlin-New York.

- (2009), On Collective Cognition and Language [in:] Language and Social Cognition. Expression of the Social Mind, ed. H. Pishwa, Mouton de Gruyter, Berlin-New York.

- (2015), Cultural Linguistics [in:] The Routledge Handbook of Language and Culture, ed. F. Sharifian, Routledge, London-New York.

Stanford Encyclopedia of Philosophy, https://plato.stanford.edu [access: 14 February 2017].

Sweetser Eve, Dancygier Barbara (2014), Figurative Language, Cambridge UP, Cambridge.

Tabakowska Elżbieta (2015), Status metafory w jezyku naukonym. Oryginat i przeketad [in:] Tekst naukowy i jego przekłtad, eds A. Duszak, A. Jopek-Bosicka, G. Kowalski, Universitas, Kraków. Tversky Barbara, Zacks Jeffrey (2013), Event Perception [in:] The Oxford Handbook of Cognitive Psychology, ed. D. Reisberg, http://www.oxfordhandbooks.com/view/10.1093/oxfordhb/9780195376746.0010001/oxfordhb-9780195376746-e-6 [access: 14 February 2017].

Wierzbicka Anna (1991), Ježyk i naród: polski los i rosyjska sud'ba, „Teksty Drugie”, 3 (9). 